Full Paper

\title{
Electrochemical Oxidation of Metolazone at a Glassy Carbon Electrode
}

\author{
A. Dora R. Pontinha, S. Carlos B. Oliveira, Ana Maria Oliveira-Brett* \\ Departamento de Química, Faculdade de Ciências e Tecnologia, Universidade de Coimbra, 3004-535 Coimbra, Portugal \\ *e-mail: brett@ci.uc.pt
}

Received: July 15,2008

Accepted: September 13, 2008

\begin{abstract}
Metolazone is a diuretic agent used in patients with edematous states and/or hypertension. The electrochemical behavior of metolazone on a glassy carbon electrode was investigated using cyclic, differential pulse, and square-wave voltammetry at different $\mathrm{pHs}$. The $\mathrm{pH}$ dependent oxidation of metolazone occurs in two consecutive steps in a diffusion-controlled mechanism and involves the formation of a main oxidation product. The first oxidation process is reversible, and involves two electrons and two protons corresponding to the oxidation of nitrogen in the sulfonamide moiety. The second oxidation process is irreversible, also occurs in the sulfonamide moiety, involves a one electrontransfer, and is followed by deprotonation to produce a cation radical, which reacts with water and yields a hydroxylated product. The diffusion coefficient of metolazone was calculated to be $3.43 \times 10^{-6} \mathrm{~cm}^{2} \mathrm{~s}^{-1}$ in $\mathrm{pH} 7.00 .1 \mathrm{M}$ phosphate buffer.
\end{abstract}

Keywords: Metolazone, Electrochemistry, Voltammetry, Oxidation mechanism, Diffusion process

DOI: $10.1002 /$ elan.200804352

\section{Introduction}

Diuretics are widely used in the treatment of congestive heart failure and hypertension. The major indications for diuretics are the enhancement of renal excretion of salt and water and lowering of blood pressure. In addition, sodium cations and chloride anions may also affect the renal readsorption and excretion of potassium, calcium, magnesium and other ions. Some diuretics increase urinary potassium excretion and can cause hypokalemia in patients treated with these medications for prolonged times [1, 2].

Diuretics are usually classified according to their chemical structures and physicochemical properties into the following four different groups: thiazides (e.g., hydrochlorothiazide and bendroflumethiazide), loop diuretics (e.g., bumetanide and furosemide), potassium-sparing diuretics (e.g., amiloride and triamterene), and carbonic anhydrase inhibitors (e.g., acetazolamide). Based on the effect of diuresis, diuretics can also be classified into high-efficiency diuretics (such as loop diuretics), medium-efficiency diuretics (such as thiazides and related compounds) and low-efficiency diuretics (such as potassium-sparing diuretics and carbonic anhydrase inhibitors) [1].

Metolazone (MT) [7-chloro-1,2,3,4-tetrahydro-2-methyl4-oxo-3-O-tolyl-6-quinazoline-sulfonamide] (Scheme 1) is structurally related to the quinazoline sulfonamide series of diuretic agents and is considered a relatively potent, longacting diuretic and natriuretic agent with minimal kaliuretic activity. Many of its pharmacological properties are comparable to the thiazide group of diuretics. MT is generally

Electroanalysis 20, 2008, No. 23, 2531-2536 given orally and is absorbed quite readily in the gastrointestinal tract. MT excretion is primarily by filtration and secretion in the kidney but a significant amount of the drug appears in the feces following usual therapeutic doses because of enterohepatic recycling. A single oral dose of MT is excreted in two to four days, with $50 \%$ excreted unchanged. Metabolites of MT are mainly hydroxylated and then further oxidized by various mechanisms [3-7].

Different methods have been applied for the determination of MT in bulk and pharmaceutical preparations including, spectrophotometric, high-performance liquid chromatographic, liquid chromatography with fluorescence detection, liquid chromatography-tandem mass spectrometry (LC-MS-MS) and LC-MS-MS with an electrospray ionization [8-10]. However, more recently, there has been a tendency for the use of less costly techniques and a reduction in the use of organic solvents since they result in high ecological costs.

Due to their high sensitivity, voltammetric methods have been successfully used for the detection and determination<smiles>Cc1ccccc1N1C(=O)c2cc(S(N)(=O)=O)c(Cl)cc2NC1C</smiles>

Scheme 1. Chemical structure of MT. 
of various pharmaceutical compounds. Moreover, investigations of the redox behavior of pharmaceutical compounds by means of electrochemical techniques have the potential for providing valuable insights into the redox reactions of these molecules [11-16]. Nevertheless, there are no electrochemical studies of MT.

The present study is concerned with the electrochemical characterization of the oxidation behavior of MT, for a wide $\mathrm{pH}$ range between 2 and 12, using cyclic, square-wave and differential pulse voltammetry at a glassy carbon electrode.

\section{Experimental}

\subsection{Materials and Reagents}

Metolazone was obtained from Sigma and used without further purification. A stock solution of $66 \mu \mathrm{M}$ MT was prepared in water and stored at $5^{\circ} \mathrm{C}$. Solutions of different concentrations of MT were prepared by dilution of the appropriate quantity in supporting electrolyte.

All supporting electrolyte solutions (Table 1) were prepared using analytical grade reagents and purified water from a Millipore Milli-Q system (conductivity $\leq 0.1 \mu \mathrm{S}$ $\left.\mathrm{cm}^{-1}\right)$.

Table 1. Supporting electrolytes, $0.2 \mathrm{M}$ ionic strength.

\begin{tabular}{rl}
\hline $\mathrm{pH}$ & Composition \\
\hline 2.2 & $\mathrm{HCl}+\mathrm{KCl}$ \\
3.4 & $\mathrm{HAcO}+\mathrm{NaAcO}$ \\
4.5 & $\mathrm{HAcO}+\mathrm{NaAcO}$ \\
5.3 & $\mathrm{HAcO}+\mathrm{NaAcO}$ \\
6.1 & $\mathrm{NaH}_{2} \mathrm{PO}_{4}+\mathrm{Na}_{2} \mathrm{HPO}_{4}$ \\
7.0 & $\mathrm{NaH}_{2} \mathrm{PO}_{4}+\mathrm{Na}_{2} \mathrm{HPO}_{4}$ \\
8.1 & $\mathrm{NaH}_{2} \mathrm{PO}_{4}+\mathrm{Na}_{2} \mathrm{HPO}_{4}$ \\
9.3 & $\mathrm{NaOH}+\mathrm{Na}_{2} \mathrm{~B}_{2} \mathrm{O}_{7}$ \\
11.1 & $\mathrm{NaOH}+\mathrm{KCl}$ \\
12.8 & $\mathrm{NaOH}+\mathrm{KCl}$ \\
\hline
\end{tabular}

Microvolumes were measured using EP-10 and EP-100 Plus Motorized Microliter Pippettes (Rainin Instrument Co. Inc., Woburn, USA). The $\mathrm{pH}$ measurements were carried out with a Crison micropH 2001 pH-meter with an Ingold combined glass electrode. All experiments were done at room temperature $\left(25 \pm 1^{\circ} \mathrm{C}\right)$.

\subsection{Voltammetric Parameters and Electrochemical Cells}

Voltammetric experiments were carried out using a $\mu$ Autolab running with GPES 4.9 software, Eco-Chemie, Utrecht, The Netherlands. Measurements were carried out using a glassy carbon electrode (GCE) $(d=1.5 \mathrm{~mm})$ working electrode, a $\mathrm{Pt}$ wire counter electrode, and an $\mathrm{Ag} / \mathrm{AgCl}$ $(3 \mathrm{M} \mathrm{KCl})$ as reference, in a $0.5 \mathrm{~mL}$ one-compartment electrochemical cell. The experimental conditions for differ- ential pulse voltammetry were: pulse amplitude $50 \mathrm{mV}$, pulse width $70 \mathrm{~ms}$, scan rate $5 \mathrm{mV} \mathrm{s}^{-1}$. For square-wave voltammetry the experimental conditions were frequency $50 \mathrm{~Hz}$ and potential increment $2 \mathrm{mV}$, corresponding to an effective scan rate $100 \mathrm{mV} \mathrm{s}^{-1}$.

The GCE was polished using diamond spray (particle size $1 \mu \mathrm{m})$ before every electrochemical assay. After polishing, the electrode was rinsed thoroughly with Milli-Q water. Following this mechanical treatment, the GCE was placed in buffer supporting electrolyte and differential pulse voltammograms were recorded until a steady state baseline voltammogram was obtained. This procedure ensured very reproducible experimental results.

\subsection{Acquisition and Presentation of Voltammetric Data}

The differential pulse voltammograms presented were background-subtracted and baseline-corrected using the moving average application with a step window of $5 \mathrm{mV}$ included in GPES version 4.9 software. This mathematical treatment improves the visualization and identification of peaks over the baseline without introducing any artifact, although the peak intensity is in some cases reduced $(<10 \%)$ relative to that of the untreated curve. Nevertheless, this mathematical treatment of the original voltammograms was used in the presentation of all experimental voltammograms for a better and clearer identification of the peaks. The values for peak current presented in all plots were determined from the original untreated voltammograms after subtraction of the baseline.

\section{Results and Discussion}

\subsection{Cyclic Voltammetry}

The voltammetric behavior using a GCE was investigated in a solution of $30 \mu \mathrm{M}$ MT in $\mathrm{pH} 70.1 \mathrm{M}$ phosphate buffer saturated with $\mathrm{N}_{2}$. The cyclic voltammograms obtained at a scan rate $v=100 \mathrm{mV} \mathrm{s}^{-1}$, show two well-separated consecutive peaks in the anodic region (Fig. 1A), but no peaks were observed in the cathodic region.

The first oxidation is reversible (Fig. 1B), peaks $1_{\mathrm{a}}-1_{\mathrm{c}}$, and the second oxidation, peak $2_{\mathrm{a}}$, at $E_{\mathrm{pa}}^{2}=+0.815 \mathrm{~V}$, corresponds to an irreversible reaction (Fig. 1A). The second scan shows the decrease of peak 2 a current and the absence of peak $1_{\mathrm{a}}$ due MT and MT oxidation products adsorption on the GCE surface.

The effect of scan rate on peak 2 a current was studied (Fig. 2). Between measurements, the electrode surface was always polished in order to assure a clean surface and to avoid possible problems from MT and MT oxidation products absorption on the GCE surface.

It was observed that increasing the scan rate the peak $2_{a}$ potential is slightly displaced to more positive values. The difference between the peak $2_{\mathrm{a}}$ potential, $E_{\mathrm{pa}}^{2}$, and the peak $2_{\mathrm{a}}$ potential at half height of peak, $E_{\mathrm{p} / 2 \mathrm{a}}^{2}$, is ca. $43 \mathrm{mV}$. Since 

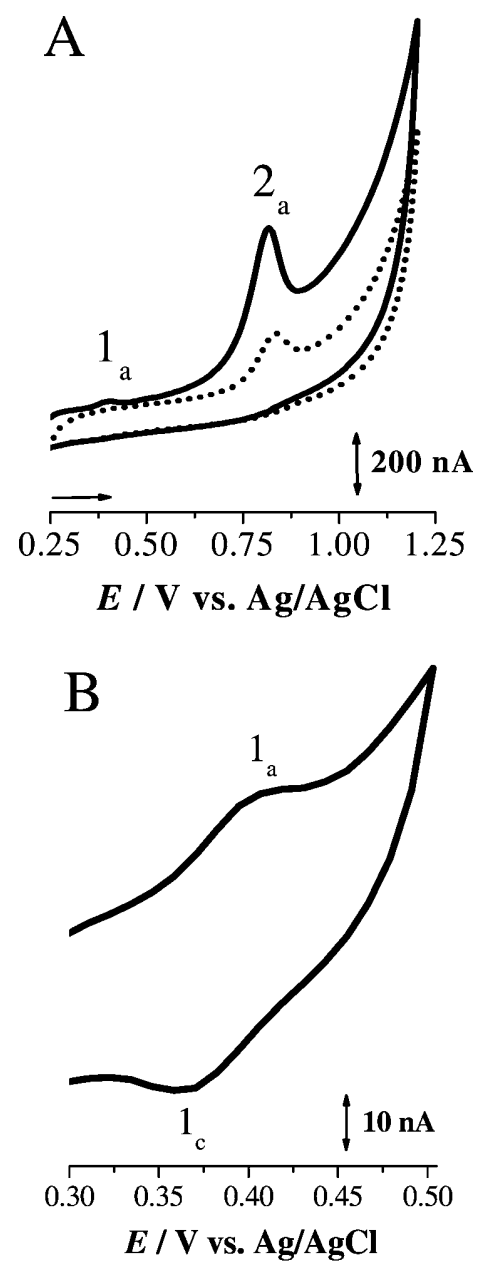

Fig. 1. Cyclic voltammograms of $30 \mu \mathrm{M}$ MT in $\mathrm{pH} 70.1 \mathrm{M}$ phosphate buffer: A) (-) first and $(\cdots \cdots)$ second scan, and B) first peak, $v=100 \mathrm{mV} \mathrm{s}^{-1}$.

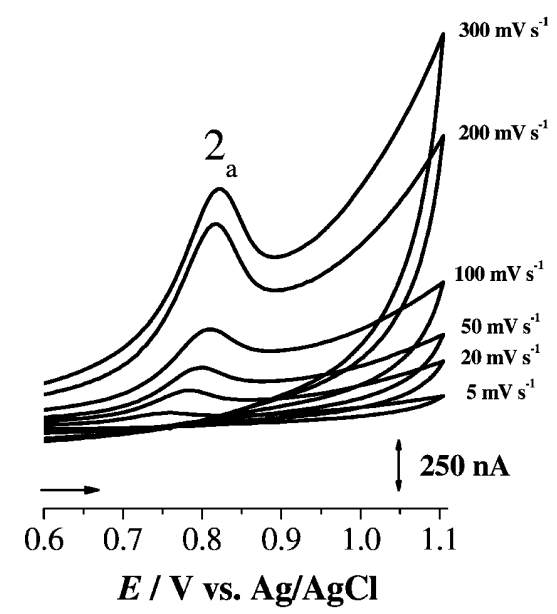

Fig. 2. Cyclic voltammograms of $30 \mu \mathrm{M}$ MT in $\mathrm{pH} 70.1 \mathrm{M}$ phosphate buffer at scan rates: $5,20,50,100,200$, and $300 \mathrm{mV} \mathrm{s}^{-1}$.

for a diffusion-controlled irreversible system $\left|E_{\mathrm{pa}}^{2}-E_{\mathrm{p} / 2 \mathrm{a}}^{2}\right|$ $=47.7 /\left(\alpha_{\mathrm{a}} n^{\prime}\right)$ where $\alpha_{\mathrm{a}}$ is the anodic charge transfer coefficient and $n$ ' the number of electrons in the rate-determining step [17], it can be calculated that $\alpha_{\mathrm{a}} n^{\prime}=1.11$.
Increasing the scan rate, the current of peak $2_{a}$ increases linearly with square root of $v$, consistent with the diffusionlimited oxidation of a solution species.

The peak current in amperes for a diffusion-controlled irreversible system is given by $I_{\mathrm{pa}}(\mathrm{A})=2.99 \times 10^{5} n\left(\alpha_{\mathrm{a}} n^{\prime}\right)^{1 / 2}$ $A[\mathrm{R}]_{\infty} D_{\mathrm{R}}^{1 / 2} v^{1 / 2}$ where $n^{\prime}$ is the number of electrons transferred during the oxidation of MT $\left(n^{\prime}=1\right.$ as shown below, Sec. 3.2), $A$ is the electrode area in $\mathrm{cm}^{2}, D_{\mathrm{R}}$ is the diffusion coefficient of $\mathrm{R}$ in $\mathrm{cm}^{2} \mathrm{~s}^{-1},[\mathrm{R}]_{\infty}$ is the concentration in mol cm$~^{-3}$ and $v$ is in $\mathrm{V} \mathrm{s}^{-1}$ [17]. By plotting $I_{\mathrm{pa}}$ vs. $v^{1 / 2}$, the value of $D_{\mathrm{R}}$ is obtained. For this calculation, the GCE electroactive area was determined from a plot of $I_{\mathrm{pc}} \mathrm{vs}$. $v^{1 / 2}$ using a solution of $500 \mu \mathrm{M}$ hexacyanoferrate (II) and the value of the diffusion coefficient of hexacyanoferrate (II) in phosphate buffer of $7.35 \times 10^{-6} \mathrm{~cm}^{2} \mathrm{~s}^{-1}$ [18], and the GCE electroactive area of $1.03 \times 10^{-5} \mathrm{~cm}^{2}$ was determined. For the measured slope of $3.72 \times 10^{-8} \mathrm{~A} /\left(\mathrm{V} \mathrm{s}^{-1}\right)^{1 / 2}$ the diffusion coefficient of $\mathrm{MT}$ in $\mathrm{pH} 70.1 \mathrm{M}$ phosphate buffer is $3.43 \times 10^{-6} \mathrm{~cm}^{2} \mathrm{~s}^{-1}$.

\subsection{The Influence of $\mathrm{pH}$}

The effect of $\mathrm{pH}$ on the electrochemical oxidation of MTwas studied over a wide $\mathrm{pH}$ range between 2 and 12 using differential pulse voltammetry. The differential pulse voltammograms (Fig. 3) were all recorded in solutions of $30 \mu \mathrm{M}$ MT in different electrolytes with $0.2 \mathrm{M}$ ionic strength (Table 1).

The reversible peak $1_{\mathrm{a}}$ only occurs in the $\mathrm{pH}$ range $2-10$ and the oxidation potential was displaced to less positive values with increasing $\mathrm{pH}$ (Figs. $3 \mathrm{~A}$ and C). In the $E_{\mathrm{pa}}$ vs. $\mathrm{pH}$ plot (Fig. 3C) the slope of the dotted line, $59 \mathrm{mV}$ per $\mathrm{pH}$ unit, shows that the mechanism of this first reversible oxidation process, peaks $1_{\mathrm{a}}-1_{\mathrm{c}}$, in aqueous media involves the same number of electrons and protons. Taking into consideration that width at half height of the MT peak $1_{\mathrm{a}}$ is $W_{1 / 2} \approx 54 \mathrm{mV}$, it can be concluded that this oxidation process involves the transfer of two electrons and two protons.

The peak $2{ }_{\mathrm{a}}$ occurs in all supporting electrolytes (Fig. 3A and $\mathrm{C}$ ). For buffer solutions between $\mathrm{pH} 2$ and 10, the potential of peak 2 is displaced to more negative values with increasing pH. In the $E_{\mathrm{pa}}$ vs. $\mathrm{pH}$ plot (Fig. 3C) the slope of the dotted line, $59 \mathrm{mV}$ per $\mathrm{pH}$ unit, shows that the mechanism of this oxidation process, Peak $2_{\mathrm{a}}$, in aqueous media also involves the same number of electrons and protons.

The number of electrons transferred, $n$, was determined by the peak width at half height $W_{1 / 2} \approx 100 \mathrm{mV}$, and is close to the theoretical value of $90 \mathrm{mV}$, corresponding to an electrochemical reaction involving the transfer of one electron [17]. Consequently, it can be concluded that oxidation process occurs with the transfer of one electron and one proton.

For $\mathrm{pH}>10$, the oxidation peak 2 a does not depend on $\mathrm{pH}$ indicating a mechanism involving only 1 electron, the MT oxidation product can undergo chemical deprotonation in 

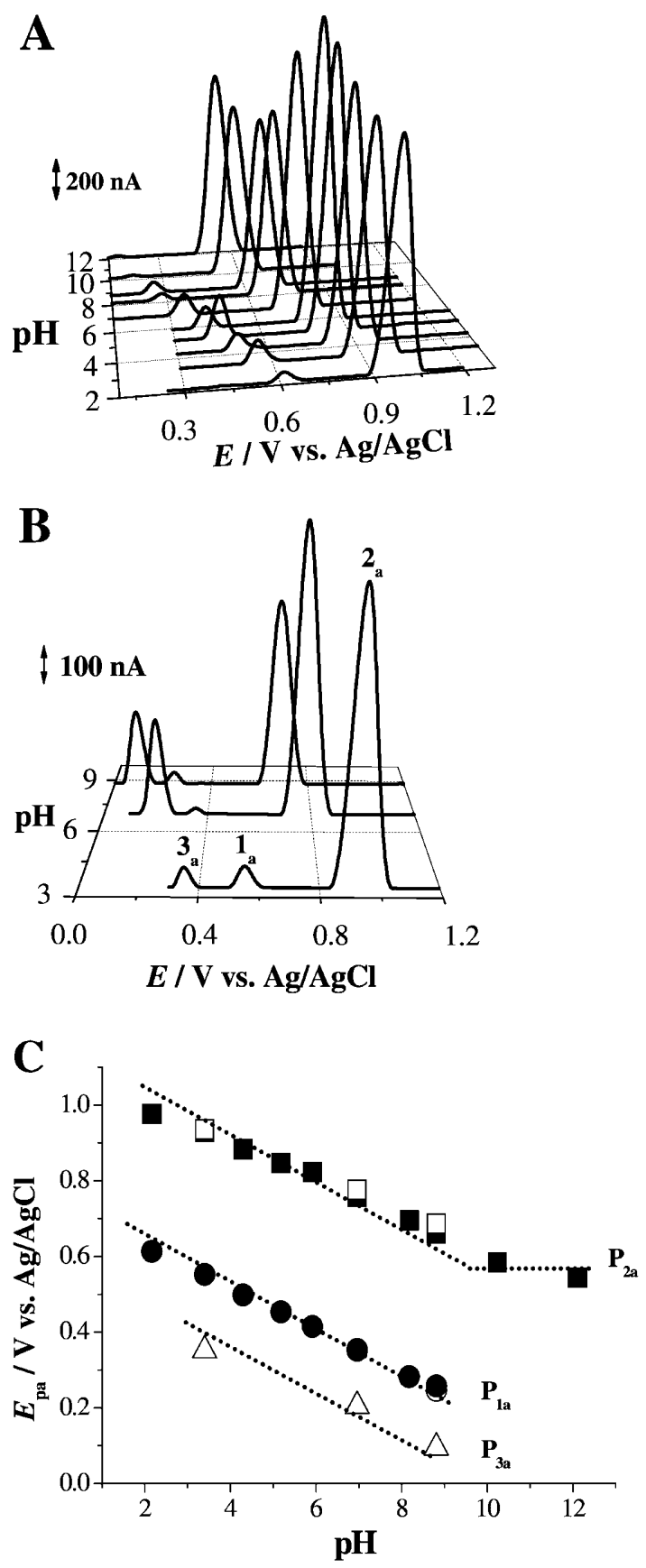

Fig. 3. 3D plots of background-subtracted differential pulse voltammograms obtained in $30 \mu \mathrm{M}$ MT as a function of $\mathrm{pH}$ : A) first and B) second scans. C) Plot $E_{\mathrm{pa}}$ vs. pH of: $(\bullet)$ peak $1_{\mathrm{a}}$ and $(\square)$ peak $2_{\mathrm{a}}$ for the first and $(\bullet)$ peak $1_{\mathrm{a}},(\square)$ peak $2_{\mathrm{a}}$ and $(\triangle)$ peak $3_{\mathrm{a}}$ for the second scans. Dotted line corresponds to $59 \mathrm{mV}$ per $\mathrm{pH}$ unit.

alkaline electrolytes [19], and the value of $\mathrm{pK}_{\mathrm{a}} \approx 10$ of MT was determined (Fig. 3C).

Successive differential pulse voltammograms in buffer solutions with pH 3.5, 7.0 and 9.0 were recorded. For all these pHs a new peak $3_{\mathrm{a}}$ occurs in the second differential pulse voltammogram (Fig. $3 \mathrm{~B}$ ) which corresponds to the oxidation of the MT oxidation product, and increasing the $\mathrm{pH}$ a decrease of the oxidation potential was observed
(Fig. 3B) and the slope of the dotted line, $59 \mathrm{mV}$ per $\mathrm{pH}$ unit (Fig. 3C) shows that the mechanism of this oxidation process, Peak $3_{\mathrm{a}}$, in aqueous media also involves the same number of electrons and protons.

The variation of peak 2 a current versus $\mathrm{pH}$ showed that the current increased with $\mathrm{pH}$ (Fig. 3A), with a maximum in the $\mathrm{pH}$ range $6-7$ using $0.1 \mathrm{M}$ phosphate buffer, and this electrolyte was used for further studies.

\subsection{Square-Wave Voltammetry}

The advantages of square-wave voltammetry are greater speed of analysis, lower consumption of the electroactive species in relation with differential pulse voltammetry, and reduced problems with poisoning of the electrode surface [17]. A greater advantage of square-wave voltammetry is the possibility to see during only one scan if the electron transfer reaction is reversible or not. Since the current is sampled in both positive and negative-going pulses, peaks corresponding to the oxidation and reduction of the electroactive species at the electrode surface can be obtained in the same experiment.

Successive square-wave voltammograms recorded in a solution of $30 \mu \mathrm{M}$ MT in different electrolytes showed similar features to the differential pulse voltammograms, i.e., oxidation peaks $1_{\mathrm{a}}, 2_{\mathrm{a}}$, and $3_{\mathrm{a}}$. Consequently, the reversibility of the peaks $1_{\mathrm{a}}$ and $3_{\mathrm{a}}$ and the irreversibility of the peak $2_{\mathrm{a}}$ were confirmed by plotting the forward and backward components of the total current obtained in a solution of MT in pH $70.1 \mathrm{M}$ phosphate buffer (Fig. 4).

Based on the results obtained a mechanism for the oxidation of MT in pH $70.1 \mathrm{M}$ phosphate buffer is proposed (Scheme 2), which is in agreement with the MT data obtained using other methodologies [3,11, 20, 21]. The first step, peak $1_{\mathrm{a}}$, is assigned to the oxidation of the nitrogen in the sulfonamide moiety and involves the transfer of two electrons and two protons. The second step occurs also in the sulfonamide moiety, peak $2_{\mathrm{a}}$, and involves one electrontransfer, followed by deprotonation to produce a cation radical, which reacts with water and yields the final hydroxylated product.

\section{Conclusions}

MT, a diuretic agent used in patients with edematous states and/or hypertension, undergoes oxidation at a glassy carbon electrode. The oxidation of MT occurs in two consecutive steps in a diffusion-controlled mechanism. The diffusion coefficient of MT in $\mathrm{pH} 7.00 .1 \mathrm{M}$ phosphate buffer was calculated to be $3.43 \times 10^{-6} \mathrm{~cm}^{2} \mathrm{~s}^{-1}$.

The first oxidation process is reversible, $\mathrm{pH}$ dependent and involves the oxidation of nitrogen in the sulfonamide moiety with the transfer of two electrons and two protons. The second oxidation process occurs also in the sulfonamide moiety is irreversible, $\mathrm{pH}$ dependent, and involves one electron and one proton transfer to produce a cation radical, 
<smiles>Cc1ccccc1N1C(=O)c2cc(N(O)O)c(Cl)cc2NC1C</smiles>

\section{Peak 1a}

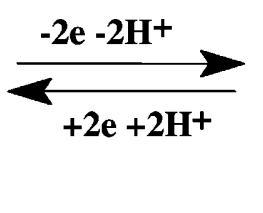<smiles>Cc1ccccc1-n1c(C)nc2cc(Cl)c(S(N)(=O)=O)cc2c1=O</smiles><smiles></smiles><smiles>CCCCCCC(C)O</smiles>

A

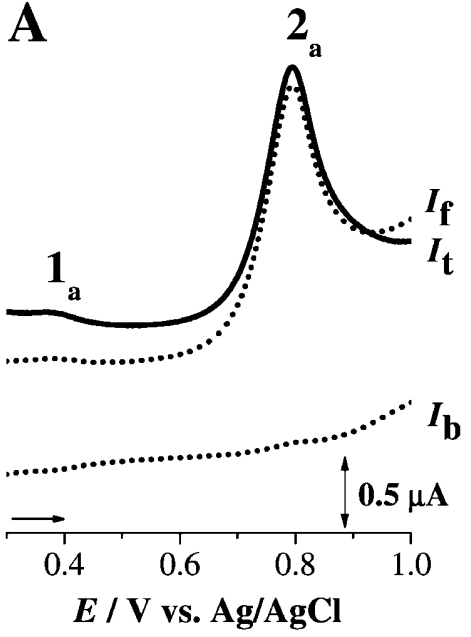

B
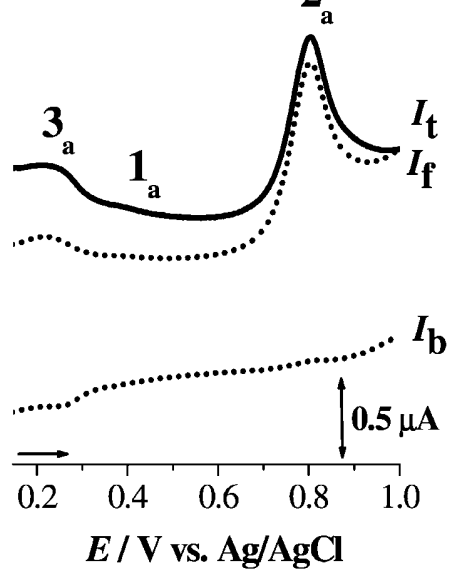

Fig. 4. Square-wave voltammogram of $30 \mu \mathrm{M}$ MT in $\mathrm{pH} 70.1 \mathrm{M}$ phosphate buffer: A) first and B) second scan; $I_{\mathrm{t}}$ : total, $I_{\mathrm{f}}$ : forward and $I_{\mathrm{b}}$ : backward; $v_{\text {effective }}=100 \mathrm{mV} \mathrm{s}^{-1}$. which reacts with water and yields a final hydroxylated product.

\section{Acknowledgements}

Financial support from Fundação para a Ciência e Tecnologia (FCT), BIID Grant PTDC/QUI/65255/2006 (A. D. R. Pontinha) and Ph.D. Grant SFRH/BD/27322/2006 (S. C. B. Oliveira), project PTDC/QUI/65255/2006 (co-financed by the European Community Fund FEDER), and CEMUC (Research Unit 285), is gratefully acknowledged.

\section{References}

[1] M. H. Lu, P. Tong, H. Xiao, S. F. Xia, X. Y. Zheng, W. Liu, L. Zhang, G. N. Chen, Electrophoresis 2007, 28, 1461.

[2] B. J. Materson, J. Am. Chem. Soc. Hypertens. 2007, 1, 373.

[3] A. Stern, Am. Heart J. 1976, 91, 262.

[4] Steinmul.Sr, J. B. Puschett, Kidney Int. 1972, 1, 169.

[5] K. Mohammad, W. David, S. J. Enna, B. B. David, in xPharm: The Comprehensive Pharmacology Reference, Elsevier, New York 2008.

[6] J. F. Winchester, R. J. Kellett, K. Boddy, P. Boyle, H. J. Dargie, M. E. Mahaffey, D. M. Ward, A. C. Kennedy, Clin. Pharmacol. Ther. 1980, 28, 611.

[7] C. L. Curry, S. M. Janda, R. Harris, J. H. Mackay, C. A. Nugent, J. Ryan, H. Schnaper, J. Schoenberger, Clin. Ther. 1986, $9,47$.

[8] M. Ciborowski, M. C. Icardo, J. V. G. Mateo, J. Martínez Calatayud, J. Pharm. Biomed. 2004, 36, 693.

[9] D. Farthing, D. A. Sica, I. Fakhry, T. W. B. Gehr, J. Chromatogr. B 1994, 653, 171.

[10] G. Wei, S. Xiao, C. Liu, J. Chromatogr. B 2007, 845, 169.

[11] O. Abdel Razak, J. Pharm. Biomed. 2004, 34, 433.

[12] V. C. Diculescu, S. Kumbhat, A. M. Oliveira-Brett, Anal. Chim. Acta 2006, 575, 190. 
[13] V. C. Diculescu, T. A. Enache, A. M. Oliveira-Brett, Anal. Lett. 2007, 40, 2860

[14] M. Macher, R. Wintersteiger, J. Chromatogr. B 1995, 709, 257.

[15] R. T. Kachoosangi, G. G. Wildgoose, R. G. Compton, Anal. Chim. Acta 2008, 618, 54.

[16] S. A. Ozkan, B. Uslu, H. Y. Aboul-Enein, Crit. Rev. Anal. Chem. 2003, 33, 155.

[17] C. M. A. Brett, A. M. Oliveira Brett, Electrochemistry: Principles, Methods and Aplications, Oxford Science University Publications, Oxford 1993.
[18] http://www.hbcpnetbase.com/, Handbook of Chemistry and Physics

[19] S. C. B. Oliveira, V. C. Diculescu, G. Palleschi, D. Compagnone, A. M. Oliveira-Brett, Anal. Chim. Acta 2007, 588, 283.

[20] A. I. Cohen, A. D. Hartman, O. N. Hinsvark, P. F. Kraus, W. Zazulak, J. Pharm. Sci. 1973, 62, 931.

[21] E. J. Belair, J. Yelnosky, A. I. Cohen, Br. J. Pharmacol. 1972, $45,476$.

\section{MALDI MS - The leading experts will guide you!}

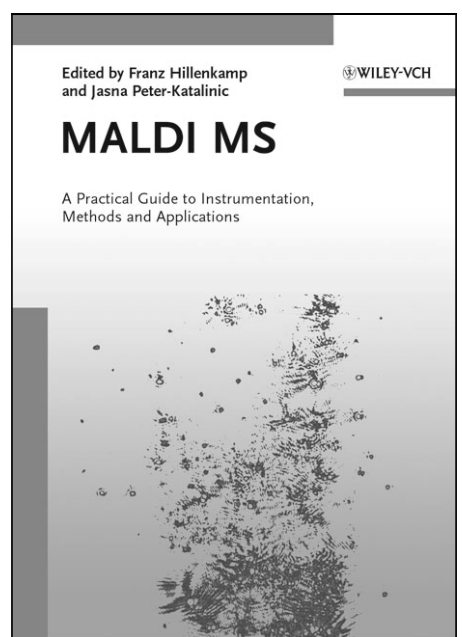

2007. XVI, 362 pages,

111 figures 26 in color,

7 tables. Hardcover.

ISBN: 978-3-527-31440-9

$€$ 99.- I£ 75.- /US\$ 135.-
FRANZ HILLENKAMP, University of Münster, Germany, and JASNA PETER-KATALINIC, University of Münster, Germany (eds.)

\section{MALDI MS}

A Practical Guide to Instrumentation, Methods and Applications

Written by one of the leading experts in the field, this first comprehensive book on MALDIMS in life sciences provides an indepth description of many different aspects and applications of this revolutionary technique.
The 2002 Nobel Prize was awarded for the development of methods for identification and structure analyses of biological macromolecules. MALDI is one of the two mass spectrometric methods besides Electrospray which is universally used for this purpose.

This unique book gives practical and educational asset for individuals, academic institutions and companies in the field of bioanalytics.
Register now for the free WILEY-VCH Newsletter! www.wiley-vch.de/home/pas
WILEY-VCH • P.O. Box $101161 \cdot D-69451$ Weinheim, Germany Fax: +49 (0) $6201-606184$

e-mail: service@wiley-vch.de•http://www.wiley-vch.de 